\title{
Política Antitruste e Credibilidade Regulatória na América Latina
}

Alexandre Gheventer

\section{INTRODUÇÃO}

problema do desenho institucional é central para a definição de políticas públicas. Dependendo de suas características, ele pode tanto atuar como incentivo ao oportunismo, na forma de populismo, captura regulatória ou outros interesses especiais, quanto favorecer cursos de ação convergentes com o interesse público.

Em determinados ambientes institucionais - em especial, na América Latina, historicamente caracterizado pelo intervencionismo e corporativismo - existe forte trade-off entre credibilidade regulatória e controle do Executivo sobre as agências responsáveis pela regulação. A maior probabilidade de exploração regulatória obriga o Executivo a limitar de forma mais severa - ou ao menos busca sinalizar o mercado que irá restringir - aqueles instrumentos de intervenção que, tipicamente, poderiam influenciar nas decisões do regulador como, por exemplo, exonerações a qualquer tempo e manipulação orçamentária, dentre outros, se assim existe o objetivo de gerar credibilidade regulatória. Dessa forma, quanto mais acelerado for o processo de privatização e reformas, mais é esperada a autonomia das agências regulatórias.

Arranjos institucionais distintos estimulam organizações à consecução de determinados resultados. Sob este ponto de vista, a política an-

DADOS - Revista de Ciências Sociais, Rio de Janeiro, Vol. 47, nº2, 2004, pp. 335 a 363. 
titruste - não essencialmente - atende, de forma intrínseca, ao interesse público ou aos interesses especiais ${ }^{1}$, existindo uma mediação institucional que estrutura as regras do jogo sobre as quais os diversos atores irão atuar.

O objetivo deste artigo é tentar apresentar alguns elementos empíricos que possam contribuir para uma melhor análise das relações entre o processo de formação de instituições e o ambiente histórico e social mais amplo, em particular, a relação entre a intensidade das reformas pró-mercado e a maior autonomia da agência antitruste. A autonomia é considerada uma variável fundamental no âmbito de um formato regulatório que busca gerar credibilidade quanto à estabilidade das regras e, desse modo, reduzir o nível de incerteza a que estão expostos os agentes econômicos.

A meta de gerar credibilidade não é natural, mas surge no contexto histórico de reformas orientadas para o mercado; entretanto, o resultado das escolhas institucionais, em cada país, pode ser distinto. Em primeiro lugar, a credibilidade não é obtida a partir de uma solução institucional única, porque o tipo de arranjo institucional necessário para o alcance desse objetivo depende do padrão regulatório prévio. Em segundo lugar, as condições macroeconômicas capazes de sustentar a criação de instituições favoráveis à formulação de compromissos críveis, entre o setor público e os agentes econômicos, podem divergir de nação para nação.

O presente artigo faz um estudo comparado do grau de autonomia dos órgãos antitrustes latino-americanos. Antes, porém, são brevemente apresentadas as experiências antitrustes dos EUA, Europa e América Latina. Como elas demonstram, os objetivos da política antitruste variam substancialmente de acordo com o ambiente institucional mais amplo. Alterações nesse ambiente modificam a estrutura de custos/benefícios da regulação, o que resulta em mudanças no seu desenho institucional.

\section{INFLUÊNCIA DO AMBIENTE INSTITUCIONAL NO DESENHO DA POLÍTICA ANTITRUSTE}

\section{Estados Unidos}

A política antitruste nasceu nos EUA, há mais de 100 anos, com a instauração do Sherman Act em 1890, não obstante o Canadá ter promul- 
gado sua lei antitruste um ano antes. Como observa Meier (1985), as origens da política antitruste estão relacionadas com o movimento populista no século XIX. Após a Guerra Civil, a economia norte-americana experimentou um período de deflação e recessão que atingiu particularmente o setor agrícola. Pequenos fazendeiros, comerciantes e trabalhadores descontentes, deslocados dos mercados pelo crescimento das grandes corporações, uniram-se. O descontentamento, ora em razão das políticas agrícolas da época, ora em função da situação privilegiada das grandes corporações em face dos pequenos homens de negócio - em especial as estradas de ferro e novos trustes como a Standard Oil -, transformou-se em ação política em favor desses grupos.

Nas suas primeiras décadas, a Lei Sherman foi obsoleta por várias razões: era muito vaga, o que permitia aos trustes encontrar brechas legais para controlar a indústria (por meio de holdings), e a Suprema Corte não concebia a produção industrial como comércio e, por isso, a indústria estava isenta da Lei. Por fim, a Lei foi mais efetiva contra os sindicatos de trabalhadores - considerados cartéis - do que contra as próprias firmas. Como conseqüência, o processo de cartelização e monopolização a profundou-se nos primeiros anos do século XX. Surgem trustes em diversas indústrias: petróleo (Standard Oil), cigarros (American Tobacco), aço (U.S. Steel), biscoitos (Nabisco), entre outros.

Após anos de domínio republicano, o Partido Democrata retornou ao poder em 1912, o que resultou no fortalecimento da capacidade governamental - legal e administrativa - de restringir o poder das grandes corporações de utilizarem métodos anticompetitivos. Duas novas leis foram aprovadas em 1914: o Clayton Act e o Federal Trade Comission (FTC) Act. A Lei Clayton procura definir condutas anticoncorrenciais de forma mais clara, listando uma série de condutas que seriam ilegais, obrigando a submissão de fusões e operações entre concorrentes. Também foi criada a FTC, uma agência administrativa especialmente encarregada de realizar investigações e adjudicações na área antitruste, que veio a compartilhar competência com a Divisão Antitruste do Departamento de Justiça [DOJ] norte-americano, responsável pela investigação criminal. Outras legislações importantes se somaram ao arcabouço legal da política antitruste norte-americana, entre elas, a Lei Robinson-Patman (1938), que proíbe a discriminação de preços; a Celler-Kefauver (1950), que trata de opera- 
ções e restrições de natureza vertical; e, mais recentemente, a Lei Hart-Scott-Rodino (1976), que obriga que as operações de fusão e aquisição sejam previamente notificadas à DOJ e à FTC, para fins de análise dos possíveis efeitos anticompetitivos de uma operação antes de sua efetiva ocorrência.

A história da jurisprudência norte-americana demonstra que a política antitruste é bastante susceptível a mudanças no sistema político. Até os anos 70, a FTC tinha uma linha de atuação bastante agressiva contra práticas e operações que pudessem ser consideradas anticoncorrenciais. Até então, prevalecia a conhecida expressão "small is beautiful". Foram abertos, no início dos anos 70, grandes processos contra a IBM, Xerox, AT\&T e mais três produtoras de cereais prontos para consumo (Kelloggs, General Mills e General Foods), todas acusadas de monopolização, entre outros casos.

No final dos anos 70, o Congresso criticou publicamente a FTC por uma série de investigações e programas realizados durante a década, considerados abusivos. O Senado ameaçou cortar verbas e extinguir o órgão. Com isso, a FTC encerrou seus casos mais polêmicos e passou a seguir uma linha de atuação menos intervencionista. Weingast e Moran (1983) argumentam que a FTC perseguia os interesses da comissão de assuntos antitrustes do Congresso durante os anos 70. Na primeira metade da década, o Congresso criticava sistematicamente a FTC pela falta de agressividade de suas ações e dava suporte para uma política antitruste ativista. Entre 1976 e 1979, quase todos os membros que formavam a coalizão dominante dentro da comissão do Congresso que envolvia a área antitruste afastaram-se, resultando, assim, na alteração das preferências da comissão.

Durante os governos Reagan/Bush, a meta da política antitruste passou a ser a da eficiência econômica, um enfoque claramente pró-indústria. Ainda que uma fusão acarretasse transferências de renda de consumidores para produtores (por exemplo, mediante aumentos de preços), esse tipo de associação poderia ser aprovado, caso gerasse aumento da eficiência; entretanto, tal critério foi parcialmente revisto na administração Clinton (ver Lande, 1996). São bastante conhecidos os processos movidos contra a Microsoft entre 1994 e 1998, por tentativa de monopolização do mercado de sistemas operacionais para computadores pessoais e do de browser, o software que permite a conexão do usuário com a Internet. Na realidade, parece ha- 
ver íntima correlação entre o partido no poder e a meta da política antitruste: conservadores tendem a ser mais pró-indústria, enquanto liberais aparentam ser mais pró-consumidores.

\section{Europa}

As diretrizes básicas da política antitruste européia estão definidas nos artigos 85 e 86 do Tratado de Roma (1958) - a proibição de acordos entre empresas e os efeitos anticompetitivos decorrentes de abuso de posição dominante. A legislação de concorrência da Comunidade Européia trata de condutas e operações com conseqüências supranacionais. As legislações nacionais européias foram implementadas após a Segunda Guerra Mundial e, em geral, seguem o arcabouço legal da Comunidade Européia, inclusive o Reino Unido. A diferença está nas regras européias que são aplicadas quando existem efeitos de mercado entre Estados-membros.

O caso europeu é radicalmente distinto do norte-americano. Com poucas exceções, como a Inglaterra, a liberalização econômica caminhou passo a passo com o desenvolvimento capitalista. Como observa Amato (1997), por diferentes razões, o desenvolvimento econômico no continente europeu não apenas tem apresentado enorme influência estatista, como também o Estado tem estimulado mais a cooperação entre empresas nacionais do que a concorrência entre elas, com o intuito de tornar competitiva a indústria doméstica - como exemplos mais significativos dessa modalidade de cultura estão a França, a Alemanha e a Itália. Mesmo no pós-guerra, e com o fim dos regimes fascistas, permaneceu a idéia de que manifestações econômicas tipificadas como cartel podem ser positivas, desde que confluam para o interesse público e os objetivos dos órgãos governamentais. Evidentemente, essa herança histórica influiu decisivamente na direção da política antitruste na Europa no pós-guerra.

Na Europa, a legislação antitruste foi implementada sob princípios bastante diversos dos preceitos norte-americanos. Conforme já observado, antes da guerra, o processo de cartelização era considerado, até mesmo, uma manifestação positiva de associação, estimulada e patrocinada pelo próprio Estado. O caso mais extremo de que se tem notícia foi o do uso do cartel pelos nazistas, na Alemanha da década de 30, como forma de extermínio dos judeus. A própria Alemanha foi o primeiro país do continente a possuir uma lei antitruste (1957), pos- 
sivelmente por forte influência norte-americana; ainda assim, o governo alemão pôde rever decisões do órgão antitruste em razão de critérios fundados no interesse nacional; sob determinadas condições, o cartel poderia ser objeto de legitimação (o chamado "cartel de crise"). Além disso, nem todos os países adotam a concorrência como principal critério de decisão, a exemplo da França, onde a legislação antitruste pretende garantir o equilíbrio econômico e social. Além disso, em muitos países - tal como a Bélgica (1960), Espanha (1963), França (1977), Portugal (1983) e Itália (1990) -, a legislação antitruste é considerada um instituto relativamente novo.

No plano europeu, a idéia de concorrência também não está livre de disputa. Embora a concorrência seja um valor importante dentro das regras legais vigentes na Comunidade Européia, não é único, já que sua importância está circunscrita a um objetivo maior: a formação de um mercado único.

Parece ser intuitivo que as naturezas pluralista da sociedade norte-americana e corporativista das sociedades européias possam influir na política antitruste. No pluralismo, a política é um processo estruturado em torno de pressões de distintos grupos de interesses, ao passo que, no corporativismo, a política é produto de uma ação concertada. Além disso, no pluralismo, o Estado é menos um ator do que um processo em contínua transformação, profundamente influenciado pelas pressões externas; no corporativismo, entende-se que o Estado seja um ator, ao lado de outros e por eles sustentado, especialmente capital e trabalho organizados, mas capaz de desenvolver políticas próprias.

Por fim, os diferentes momentos históricos de implantação da política antitruste, nos EUA e na Europa, influenciaram, decisivamente, na sua evolução. Não apenas no continente europeu sempre houve, por razões culturais, maior aceitação do poder econômico privado do que nos EUA, como ainda a implementação das legislações européias ocorreu quando a realidade da maior parte dos mercados era oligopolística.

O resultado dessa matriz histórica e cultural foi uma política antitruste que não nega o poder econômico privado, mas condiciona-o a interesses mais gerais de política industrial, regional e social. As operações ou acordos entre empresas que impliquem maior concentração 
são explicitamente aceitos, desde que consistentes com os objetivos daquelas políticas. O resultado é uma lei bem mais rígida, em determinadas situações, do que a legislação norte-americana. Assim, o resultado político da implantação da política antitruste em um ambiente com instituições baseadas no compromisso entre atores, compromisso este fundado em preocupações com políticas mais gerais, implicou, paradoxalmente, em maior autonomia política, bem menos vulnerável a grupos de interesse específicos, como no caso norte-americano ${ }^{2}$.

Quadro 1

Instituições e Política Antitruste: Europa e EUA

\begin{tabular}{|c|c|c|}
\hline & Estados Unidos & Europa \\
\hline $\begin{array}{l}\text { Valores Culturais e } \\
\text { Históricos }\end{array}$ & $\begin{array}{l}\text { Competição e liberdade } \\
\text { econômica }\end{array}$ & $\begin{array}{l}\text { Cooperação e } \\
\text { protecionismo estatal }\end{array}$ \\
\hline Ambiente Institucional & $\begin{array}{l}\text { Pluralismo e pouco } \\
\text { domínio do Executivo } \\
\text { sobre o processo de } \\
\text { formação das leis }\end{array}$ & $\begin{array}{l}\text { Corporativismo e maior } \\
\text { possibilidade de o } \\
\text { Executivo exprimir suas } \\
\text { preferências no processo } \\
\text { legislativo }\end{array}$ \\
\hline Articulação & $\begin{array}{l}\text { Estado e grupos sociais } \\
\text { diversos (formais e } \\
\text { informais) }\end{array}$ & $\begin{array}{l}\text { Estado e grupos sociais } \\
\text { organizados (capital e } \\
\text { trabalho) }\end{array}$ \\
\hline $\begin{array}{l}\text { Objetivos da Política } \\
\text { Antitruste }\end{array}$ & $\begin{array}{l}\text { Concorrência como um } \\
\text { fim }\end{array}$ & $\begin{array}{l}\text { Concorrência como } \\
\text { instrumento }\end{array}$ \\
\hline
\end{tabular}

\section{América Latina}

Na América Latina prevaleceu o chamado modelo de substituição de importações, que, necessariamente, foi acompanhado pela atuação do Estado como produtor e pela significativa participação das multinacionais. A região apresenta certos paralelos com a Alemanha e o Japão, casos clássicos de desenvolvimento tardio, que tiveram de estimular a monopolização e a cartelização para a obtenção de excedentes econômicos que pudessem diminuir os gaps entre estes países e os que já se haviam desenvolvido, como, por exemplo, a Inglaterra e os EUA.

Por razões históricas, as instituições latino-americanas, antes de serem produtos de acordos entre os diversos atores sociais, foram criadas pelo Estado como estratégia de desenvolvimento tardio, que exi- 
gia concentração e centralização de capital. Nesse contexto, os atores políticos deparam-se com duas restrições: a primeira delas, uma sociedade caracterizada por níveis extremos de desigualdade socioeconômica; e a segunda, um baixo grau de consistência institucional no setor público, que propicia seu uso para fins privados, aliado ao fato histórico de o Estado ter se estabelecido de forma impositiva primeiramente a qualquer esforço de mobilização social. O corporativismo latino-americano, diferentemente do europeu, corresponde a um formato organizacional imposto pelo Estado, institucionalizado previamente à consolidação do capitalismo industrial e aos esforços autônomos de mobilização social.

E mais ainda se pode acrescentar: como o corporativismo estatal é caracterizado por uma distribuição assimétrica de recursos decisórios em favor do Estado, as demandas de grupos sociais são absorvidas por meio de práticas de cooptação, o que dá origem a um determinado conjunto de políticas regulatórias do tipo rent-seeking. Na Europa, ao contrário, o corporativismo diz respeito a arranjos que emergem entre atores que possuem igual acesso a instâncias de decisão, o que possibilita a formulação de políticas públicas de base consensual.

Qual o papel da política antitruste nesse ambiente institucional? Evidentemente, nenhum, ou, no máximo, simbólico. Mesmo nos anos 80, caracterizados pela crise do Estado como mediador de conflitos distributivos da sociedade em razão da interrupção do crescimento e elevação das taxas inflacionárias a níveis inéditos, o impacto das decisões dos órgãos latino-americanos ainda era praticamente nulo. Ao mesmo tempo, encontramos nos anos 80 uma das condições prévias fundamentais para a efetiva implementação da política antitruste na década seguinte: a elevação substancial dos custos estatais para ofertar políticas corporativistas e seu conseqüente enfraquecimento como estratégia eleitoral.

\section{DESENVOLVIMENTO RECENTE DA POLÍTICA ANTITRUSTE NO MUNDO - DESREGULAÇÃO E REGULAÇÃO ANTITRUSTE}

Os anos 90 caracterizaram-se por um rápido processo de liberalização, especialmente dos países em desenvolvimento. A tendência dos governos, ao facilitarem fluxos de investimentos externos diretos, refletiu-se não só nas significativas mudanças em sua estrutura regula- 
tória como também no rápido aumento dos tratados de investimento bilaterais.

Tabela 1

Mudanças Regulatórias, 1991-1996

\begin{tabular}{l|c|c|c|c|c|c}
\hline Item & $\mathbf{1 9 9 1}$ & $\mathbf{1 9 9 2}$ & $\mathbf{1 9 9 3}$ & $\mathbf{1 9 9 4}$ & $\mathbf{1 9 9 5}$ & $\mathbf{1 9 9 6}$ \\
\hline Número de países que introduziram mudanças em & & & & & & \\
$\quad$ seus regimes de investimento & 35 & 43 & 57 & 49 & 64 & 65 \\
№ de regimes: & 82 & 79 & 102 & 110 & 112 & 114 \\
$\quad$ em direção a uma maior liberalização ou pro- & & & & & & \\
$\quad$ moção & 80 & 79 & 101 & 108 & 106 & 98 \\
em direção a um maior controle & 2 & - & 1 & 2 & 6 & 16 \\
\hline
\end{tabular}

Fonte: World Investment Report 1997 - Transnational Corporations, Market Structure and Competition Policy. United Nations on Trade and Development, 1997.

Dos 65 países estudados pela United Nations Conference on Trade and Development - UNCTAD, em 1996, 55 eram países em desenvolvimento. As principais mudanças verificadas incluem a abertura de indústrias anteriormente fechadas para investimentos estrangeiros. Em particular, na América Latina, as reformas econômicas implementadas por boa parte dos países desde meados dos 80 significaram a mudança de um tipo de estratégia de desenvolvimento tradicional na região - o modelo de substituição de importações - para um processo de inserção global. Essa nova realidade também foi expressa no crescimento dos acordos regionais ou bilaterais de investimento. Dos 53 acordos bilaterais dos países do continente americano, 50 foram negociados nos anos 90; dessas alianças, 37 foram negociadas entre países latino-americanos, além do que, foram celebrados oito acordos de investimento no âmbito dos tratados regionais ou de integração, nos mesmos anos 90. Ao lado dessa nova realidade regulatória, diversos países latino-americanos têm acelerado seus respectivos processos de privatização. Portanto, a entrada de investimentos externos, nos últimos anos, na América Latina foi decisivamente influenciada por esses programas, ainda em fase de implementação em diversos países.

O resultado tem sido o aumento do fluxo de investimentos externos para a região. De acordo com a UNCTAD, esses fluxos representaram cerca de 18,4\% do Produto Interno Bruto - PIB, contra 6,4\% em 1980 e 11,6\% em 1990. 
A liberalização da entrada desses fluxos de investimentos contribuiu para aumentar não só o poder de contestação dos mercados nacionais, mas também a competição interna; por outro lado, alguns estudos têm associado, positivamente, atividade transnacional e concentração industrial/de mercado (ver, p. ex., Davies e Lyons, 1996). Essa associação tende a ser mais forte em mercados nos quais a competição ocorre mais por meio da diferenciação de produtos e inovação do que da de preços. A indústria transnacional tende a superar a desvantagem de operar em um ambiente estranho por outras vantagens, como, por exemplo, tecnologia, práticas gerenciais ou organizacionais superiores, domínio de marcas fortes ou redes de marketing.

A participação mais intensiva de empresas transnacionais nos mercados nacionais, especialmente nos mercados altamente concentrados, em grande parte envolvendo produtos diferenciados, com fortes marcas associadas, vem aumentando a probabilidade de condutas anticompetitivas, a exemplo da formação de cartéis ou colusões tácitas e das operações de compra de empresas nacionais, objetivando a monopolização ou o aumento do poder de mercado ou mesmo objetivando comportamentos predatórios (por exemplo, mediante preços de transferência de produtos e serviços, entre a matriz e a subsidiária, que venham a possibilitar a venda desses preços abaixo do custo).

O resultado desse processo de integração global seria a tendência de adoção de leis de concorrência que controlassem possíveis práticas restritivas. De acordo com a UNCTAD, em 1980, menos de quarenta países possuíam leis de concorrência. A partir de 1989, com as reformas econômicas na Europa Central e Europa Oriental, o número dessas leis aumentou rapidamente. Na América Latina, a maior parte delas foi implementada ou revista na década de 90. Em 1996, setenta países as possuíam.

À primeira vista, podemos supor existir íntima correlação entre a introdução de leis de concorrência, em países em desenvolvimento, e a substituição de um modelo econômico baseado em um alto grau de intervenção estatal por regimes de mercado. Evidentemente, a abertura da economia e os programas de privatização representam apenas uma das muitas facetas que caracterizariam um típico regime de mercado. De qualquer forma, parece razoável haver relação entre a intensidade e a abrangência de reformas econômicas pró-mercado, entre as quais se incluem a liberalização econômica e as privatizações, 
além de maior preocupação com a regulação eficiente desse próprio mercado, que se refletiria na elaboração e implementação de leis de concorrência.

\section{CREDIBILIDADE REGULATÓRIA: REFORMAS PRÓ-MERCADO E AUTONOMIA}

A autonomia da agência é considerada uma variável crucial para uma maior eficácia da política de defesa da concorrência. Em artigo recente (Jornal do Brasil, 1/8/1999, p. 4), Gustavo Franco afirma que a equipe do Ministério da Justiça, durante a discussão da legislação de defesa da concorrência em 1993, tinha mais interesse na criação de um braço operacional para combater "preços abusivos", em especial no setor de farmacêuticos, do que em estabelecer uma legislação moderna de fomento à competição.

Autonomia significa capacidade institucional do órgão de tomar decisões e de executá-las (Przeworski, 1995:77). O termo "autonomia" aproxima-se do significado de "insulamento burocrático". De acordo com Nunes (1996), o insulamento burocrático é o processo de proteção do núcleo técnico do Estado contra interferências oriundas do público ou de outras organizações intermediárias. O Executivo, ao promover o insulamento burocrático de determinado órgão, procura protegê-lo das incertezas inerentes a um ambiente institucional mais amplo, por exemplo, do Congresso, dos partidos e de demandas privadas, em prol de objetivos governamentais considerados de natureza "técnica" pelo próprio Executivo.

Nesse sentido, a autonomia relaciona-se com a necessidade estatal de criar um ambiente operativo em um determinado momento, para que o órgão alcance finalidades preestabelecidas. A capacidade estatal e o próprio interesse do Executivo em gerar esse ambiente operativo dependem de fatores estruturais, institucionais e políticos.

O interesse de se conceder autonomia ao órgão está relacionado com problemas ocasionados pela rápida mudança em direção a um elevado grau de liberdade econômica. A ausência de um eficiente organismo regulador de mercado, em um ambiente de elevada liberdade econômica em que se pressupõe o enfraquecimento dos mecanismos de controle estatais diretos, pode conduzir a instabilidades e elevar as 
incertezas dos agentes econômicos, influindo, portanto, negativamente na taxa de investimento da economia.

A credibilidade regulatória não decorre de um maior ou menor intervencionismo da política antitruste, mas da estabilidade das regras e da expectativa de que as decisões tomadas não obedeçam a conveniências políticas de curto prazo. Uma decisão antitruste, eventualmente intervencionista ou condescendente com condutas ou operações, pode, ou não, ter conotações políticas. Se a agência possui reputação técnica, suas decisões futuras têm maior previsibilidade, o que, em si, já estimularia o fluxo de investimentos. A credibilidade regulatória - que é independente do grau de intervencionismo da agência sobre o mercado - permite que o spread relacionado ao risco do investimento seja menor, reduzindo, assim, o custo do capital.

A autonomia é uma das condições cruciais para a formulação de uma política antitruste crível. Maior ou menor vulnerabilidade da política antitruste a influências externas depende do grau de autonomia da organização responsável por sua formulação.

\section{Liberalização Econômica e Grau de Autonomia da Política Antitruste}

Uma proxy quanto ao maior ou menor sucesso das estratégias de políticas, no sentido da implantação de regimes de mercado, são os índices de liberdade econômica elaborados por Gwartney e Lawson (2002) e Johnson e Sheehy (2002). Por conta da complexidade dos fatores envolvidos na construção desses índices, não será aqui discutida mais profundamente a metodologia utilizada pelos autores, considerando, em princípio, índices válidos de mensuração do grau de liberdade de regimes econômicos. Em Johnson e Sheehy, quanto menor o índice, maior a liberdade econômica; já em Gwarney e Lawson, quanto maior o índice, maior a liberdade econômica.

Consideremos, como hipótese inicial, que economias mais liberalizadas tendem a possuir políticas antitrustes com maior grau de autonomia. Uma fonte disponível para a avaliação do grau de autonomia de órgãos de defesa da concorrência é a pesquisa elaborada pela Global Competition Review - GCR. A metodologia adotada pela GCR buscou estabelecer parâmetros de comparação a partir de seis aspectos de uma agência de defesa da concorrência: o controle de fusões, a repressão a práticas anticompetitivas, a qualidade do corpo técnico, a ade- 
quação dos procedimentos administrativos, o grau de independência da autoridade e a liderança. Cada agência recebeu de uma a cinco estrelas, dependendo da avaliação de sua comunidade de usuários. A pesquisa é apenas uma proxy do desempenho dos órgãos, uma vez que se fundamenta na expectativa das comunidades profissionais (como escritórios de advogados), que pode variar significativamente de país para país. O Quadro 2 apresenta o ranking dos órgãos de defesa da concorrência formulado pela pesquisa da GCR:

Apesar das limitações de ordem metodológica, o estudo apresenta indicadores úteis de análise. O Japão, por exemplo, possui apenas uma estrela, o que é esperado, tendo em vista sua pequena tradição na área. Vários países, que, em tese, possuem maior tradição liberal (o Canadá, inclusive, possui a legislação antitruste mais antiga do mundo), estão no grupo das duas estrelas. A Alemanha, com menor tradição em política antitruste do que os EUA, aparece na frente, com cinco estrelas.

O Brasil surge no grupo de países com três estrelas. Na verdade, a boa performance brasileira deve-se, principalmente, à gestão do presidente do Conselho Administrativo de Defesa Econômica-CADE, Gesner Oliveira (1996-2000), que mereceu cinco estrelas no item "liderança". Durante seus dois mandatos, houve clara preocupação de se promover a cultura concorrencial (promoção de seminários, programas de intercâmbio etc.), bem como de tornar mais transparente suas atividades, por meio de relatórios anuais, estatisticamente bem detalhados, e da disponibilização eletrônica de decisões e textos legais pela internet.

Por outro lado, no item "independência", o Brasil apresenta apenas uma estrela e meia, o que o coloca entre os países cujo órgão antitruste possui menor grau de independência do mundo, superando apenas Portugal. Os termos da avaliação do estudo são aqui transcritos:

"[...] in terms of independence, a point often made is that the Brazilian government is not seen to interfere directly in CADE's affairs, unlike the situation in some other Latin American countries. At the same time, CADE is seen not to antagonize the government. 'Gesner has been very careful', says a competition expert in a top São Paulo firm. 'For every decision he's made, he's also made political decisions about what the government will tolerate'". 
Alexandre Gheventer

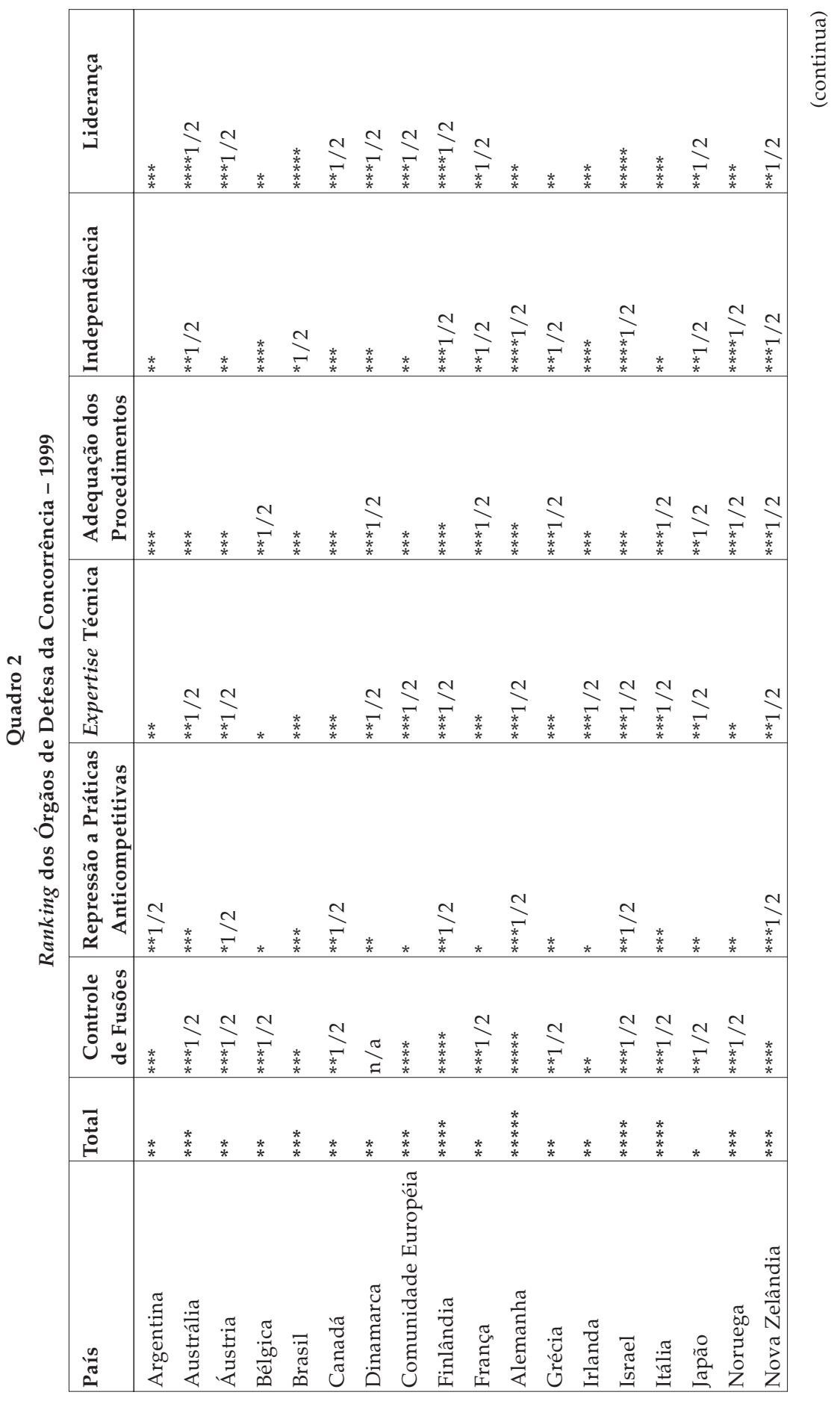


Política Antitruste e Credibilidade Regulatória na América Latina

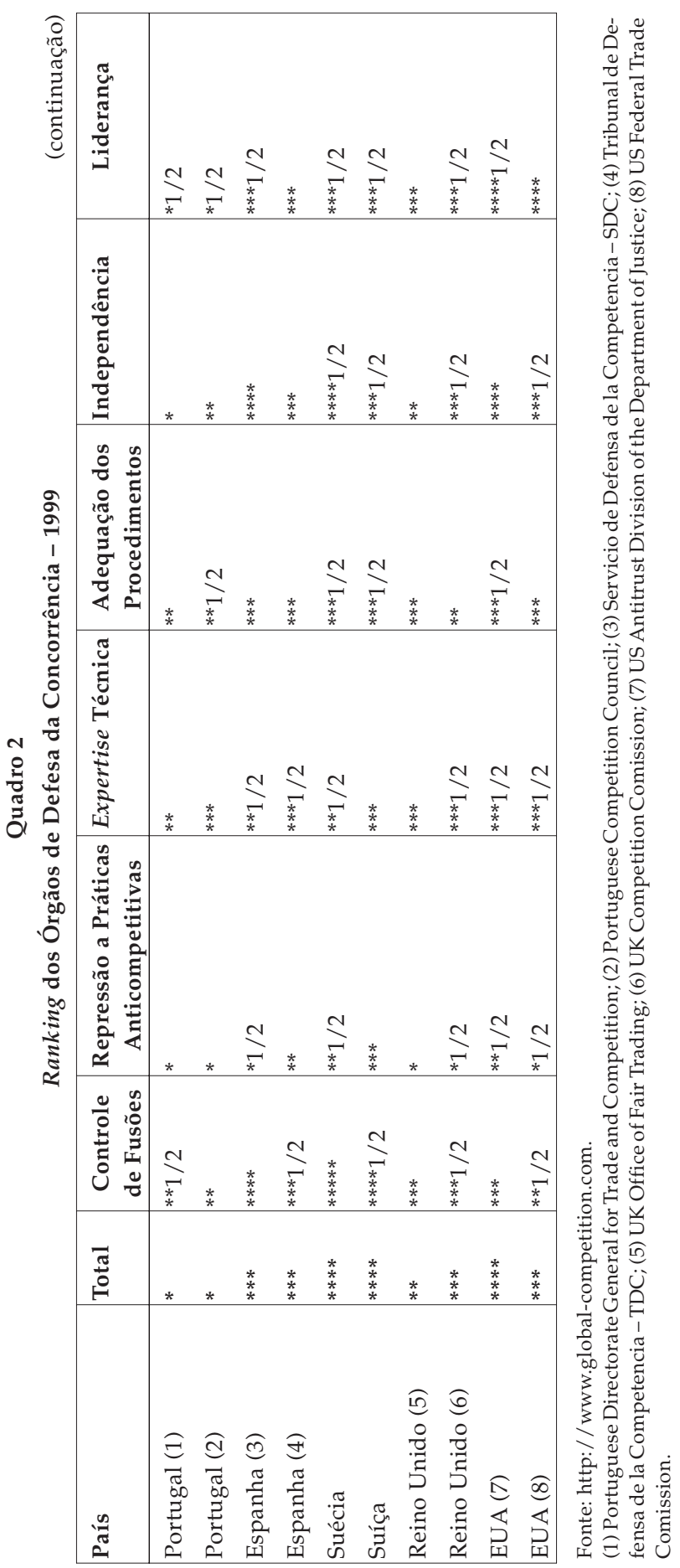




\section{Alexandre Gheventer}

A análise igualmente atribui a divisão de responsabilidades do CADE com dois outros órgãos (Secretaria de Direito Econômico SDE e Secretaria de Acompanhamento Econômico - SEAE) como um elemento que afeta, negativamente, a independência do referido Conselho Administrativo.

Os Gráficos 1 e 2 apresentam a relação entre o índice de liberdade econômica e o índice GCR:

\section{Gráfico 1}

Relação entre o Índice Gwarney e Lawson (em 2000) e a Autonomia, de acordo com Global Competition Review em 1999

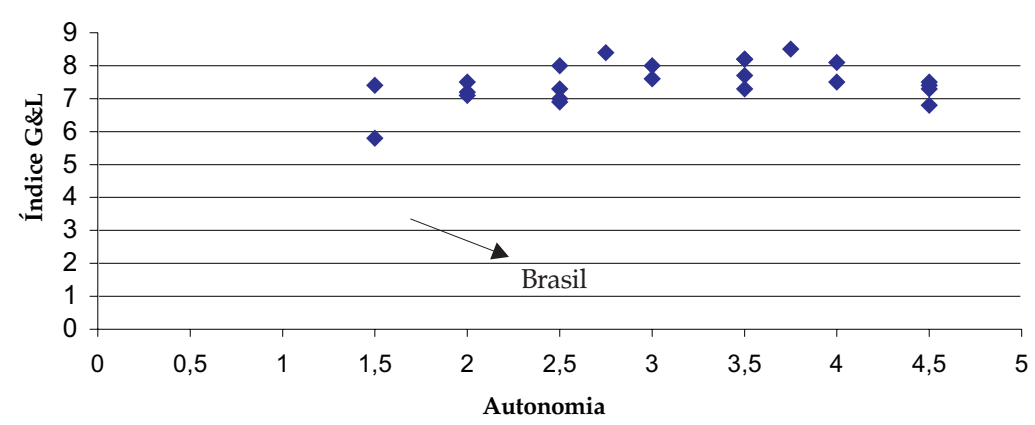

Correlação $=0,3161427 ; \mathrm{R} 2=0,099946$

\section{Gráfico 2}

Relação entre o Índice Johnson e Sheehy (em 1999) e a Autonomia, de acordo com Global Competition Review em 1999

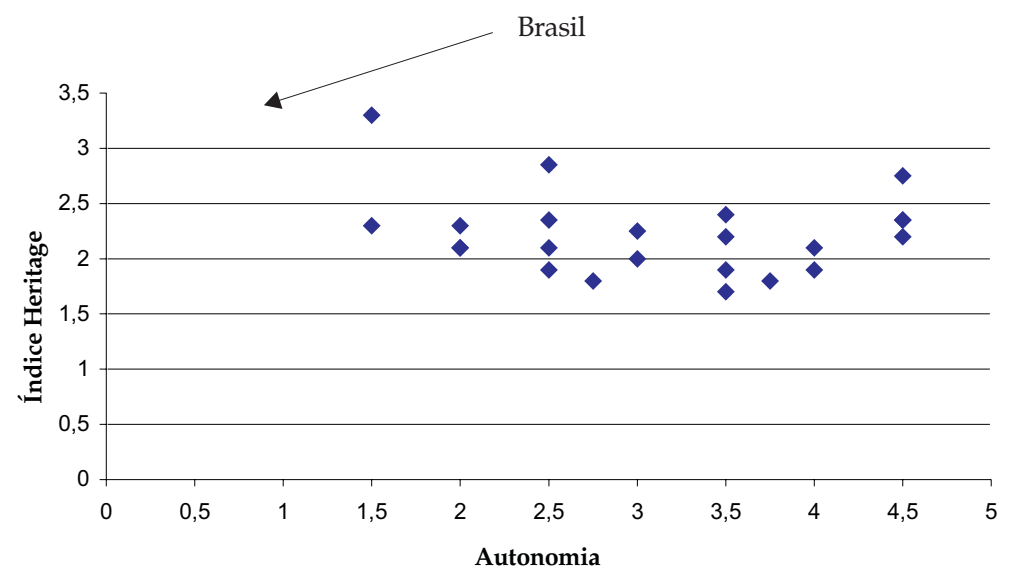

Correlação $=-0,19903 ;$ R2 = 0,039614 
Observe que os resultados, embora não significativos, possuem os sinais esperados. Nos dois gráficos, o Brasil aparece como o país com o menor grau de autonomia e os índices mais desfavoráveis de liberdade econômica. A fraca relação entre as variáveis não invalida a hipótese para países em processo de transição para economias liberalizadas. A maior parte da amostragem da GCR é composta por países com elevado grau de desenvolvimento e estabilidade institucional; é esperada uma maior flexibilidade administrativa nesses países. Por sua vez, em nações com maior tradição corporativista e de intervenção estatal - como Brasil e Argentina -, a autonomia torna-se a variável mais relevante para a provisão de credibilidade aos agentes econômicos privados sobre os resultados da política regulatória.

\section{Grau de Autonomia Antitruste na América Latina}

Atualmente, dez países da América Latina e do Caribe possuem legislação de defesa da concorrência (OEA, 1997): Argentina (1919, revisada em 1946, 1980 e 1999), Brasil (1962, revisada em 1990 e 1994), Colômbia (1959, suplementada em 1992), Costa Rica (1994), Chile (1959, revisada em 1973 e incorporada em 1979), Jamaica (1993), México (1934, substituída em 1992), Panamá (1996), Peru (1991, modificada em 1994 e 1996) e Venezuela (1991). Além disso, países como Bolívia, Equador, Honduras, El Salvador, República Dominicana, Paraguai, Guatemala, Nicarágua, Trinidad e Tobago e Uruguai têm debatido a futura implementação de legislação sobre a matéria.

Como os dados da GCR não incluem a maior parte das legislações antitruste latino-americanas, foi desenvolvido um índice para a região que ordenasse os níveis de autonomia das agências existentes. Todos os órgãos possuem autonomia funcional, seja na forma de superintendências (Colômbia e Venezuela), seja sob a modalidade de comissões. A autonomia efetiva do órgão, porém, depende de outros fatores, e, nesse caso, as fórmulas institucionais são bastante distintas; para tanto, considerou-se que o grau de autonomia da política antitruste depende dos seguintes fatores:

1ํ) Decisão pluripessoal ou unipessoal. Das dez agências de concorrência latino-americanas, oito são comissões e duas são superintendências. É assumida a hipótese de que comissões - que se caracterizam por tomar decisões de natureza pluripessoal - possibilitam maior autonomia decisória, mesmo porque é mais custoso para uma pessoa (públi- 
ca ou privada) influenciar, em um processo decisório compartilhado, três ou mais decisores do que quando a decisão for de responsabilidade de um único indivíduo.

2) Autonomia orçamentária. Supõe-se que a existência de recursos próprios reduz o grau de subordinação da agência em relação à administração direta, que pode direcionar as decisões por meio de ameaças/promessas de alterações no orçamento. Aqui é levado em conta que "recursos próprios" não são aqueles necessariamente originários, por exemplo, de taxas cobradas das empresas fiscalizadas, mas, sim, que independem diretamente de eventual instância administrativa superior.

3o) Processo de nomeação compartilhado ou centralizado. O processo de nomeação compartilhado favorece a representação plural dos interesses e reduz o compromisso político dos reguladores com o Poder Executivo. Em quase todos os países (oito), o Poder Executivo domina o processo de nomeação. Em dois países (Chile e Argentina), o desenho institucional garante a representação dos interesses de outras instâncias na agência.

4) Critério de escolha prevê especialização técnica. A exigência de especialização técnica, isto é, a reputação e o conhecimento da matéria, por parte dos reguladores, de preferência com backgrounds distintos (p. ex., economistas e advogados), reduz o risco de captura e eleva a legitimidade social das decisões.

5) Estabilidade do cargo. A estabilidade no cargo significa que os reguladores estão protegidos de ameaças de demissão como instrumento de persuasão para a formulação de determinadas decisões. Os seguintes elementos determinam a estabilidade dos reguladores à frente da agência: a existência de mandatos fixos, sua duração e o grau de liberdade do Executivo para afastar o regulador do cargo. A existência de mandatos fixos, com tempo de delegação razoável (pelo menos igual ao tempo do mandato presidencial) e os casos em que a remoção pode ocorrer apenas em situações previstas por lei, permitem a continuidade da política vis-à-vis as alterações no ambiente político.

6-) Influência de outros órgãos da administração direta no processo decisório. A ingerência de outros órgãos da administração direta nos procedimentos da agência - como poder para instaurar processos, proceder a investigações, realizar acordos etc. - também reduz a sua auto- 
nomia na medida em que sua autoridade, para mediar e arbitrar conflitos, pode ser questionada. Como os órgãos da administração direta são instâncias unipessoais totalmente subordinadas ao Poder Executivo, as decisões finais da agência de concorrência podem estar, ao menos parcialmente, condicionadas às suas preferências políticas.

7) Autoridade para aplicar sanções. Se a agência, após a realização de todas as investigações e análises, não tiver autoridade para aplicar as sanções consideradas necessárias e que estejam previstas em lei, ou mesmo se as sanções forem revistas por outra instância administrativa, evidentemente ocorrerá perda de credibilidade institucional.

O Quadro 3 resume os resultados encontrados:

O critério para a mensuração do grau de autonomia é bastante simples. Foi atribuído o valor de 0,5 ponto para cada elemento que fosse determinante para o grau de autonomia da política antitruste. A ausência de uma característica institucional que favorecesse a autonomia implicou pontuação igual a zero. Ao final, os pontos parciais foram somados, conforme a última coluna do Quadro 3. Quanto maior a pontuação, maior o grau de autonomia; existe relativa dispersão no grau de autonomia dos órgãos responsáveis pela formulação da política. A Argentina, com 4 pontos, teria a agência antitruste com maior grau de autonomia, ao passo que a Colômbia teria a menos autônoma, com 1,5 ponto.

Entretanto, deve-se observar que a aproximação é imperfeita por três motivos. Em primeiro lugar, possivelmente, alguns fatores - como tempo de mandato - são mais importantes que outros na determinação do grau de autonomia. Em segundo, podem existir discordâncias quanto à eficácia do texto legal para o alcance de determinado objetivo. Como exemplo, seria citado que no Brasil se prevê apenas "notório saber econômico ou jurídico", o que, para alguns, talvez seja insuficiente para garantir a especialização técnica. Em terceiro lugar, as legislações não captam outros elementos importantes, externos ao texto legal, para a determinação da autonomia das agências ${ }^{3}$.

\section{Autonomia e Liberalização Econômica na América Latina}

Países que conheceram um aumento mais expressivo da liberdade econômica seriam mais propensos a implementar legislações antitruste? O índice de Gwartney e Lawson, por possuir séries qüinqüe- 
Alexandre Gheventer

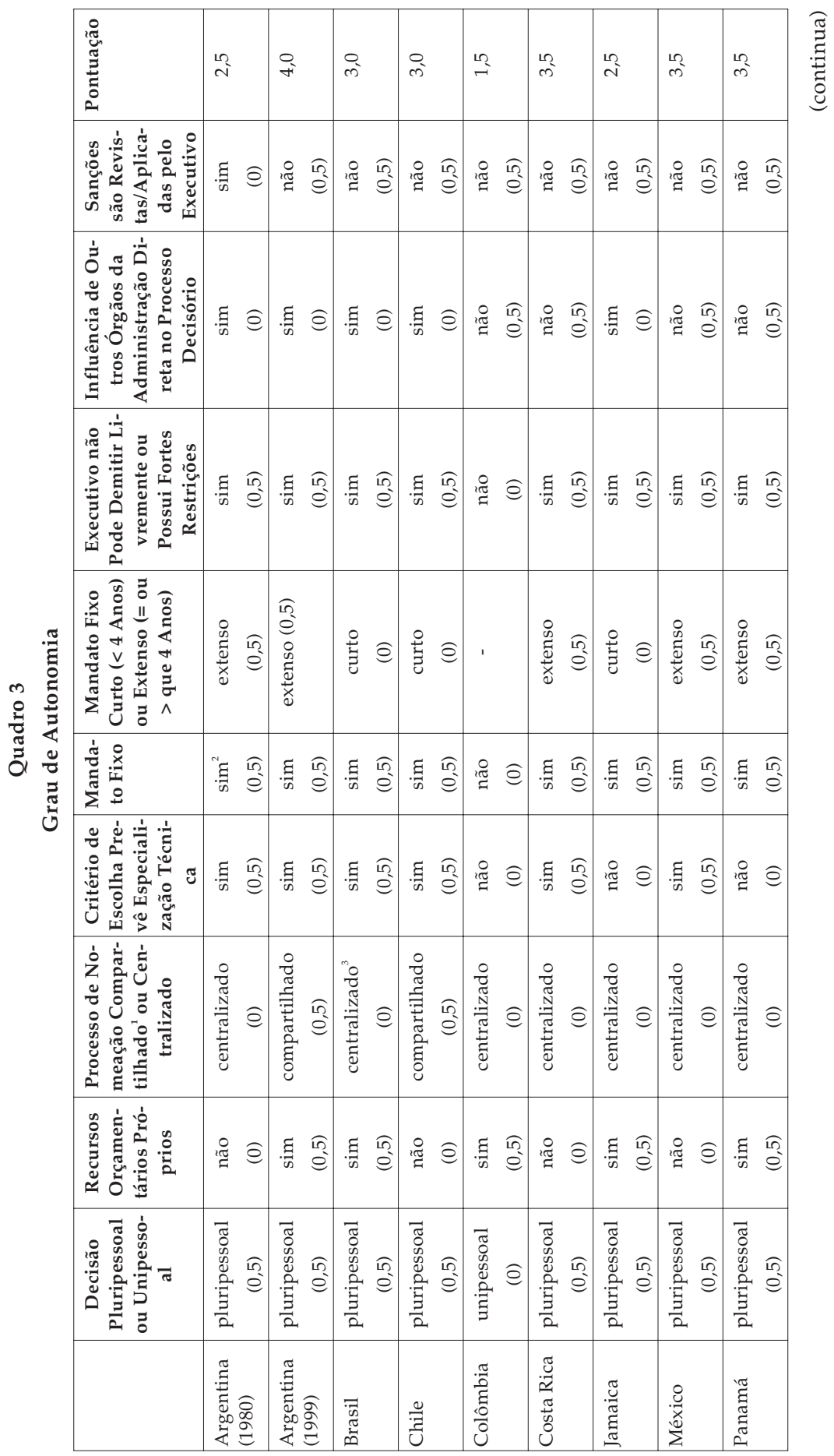


Política Antitruste e Credibilidade Regulatória na América Latina

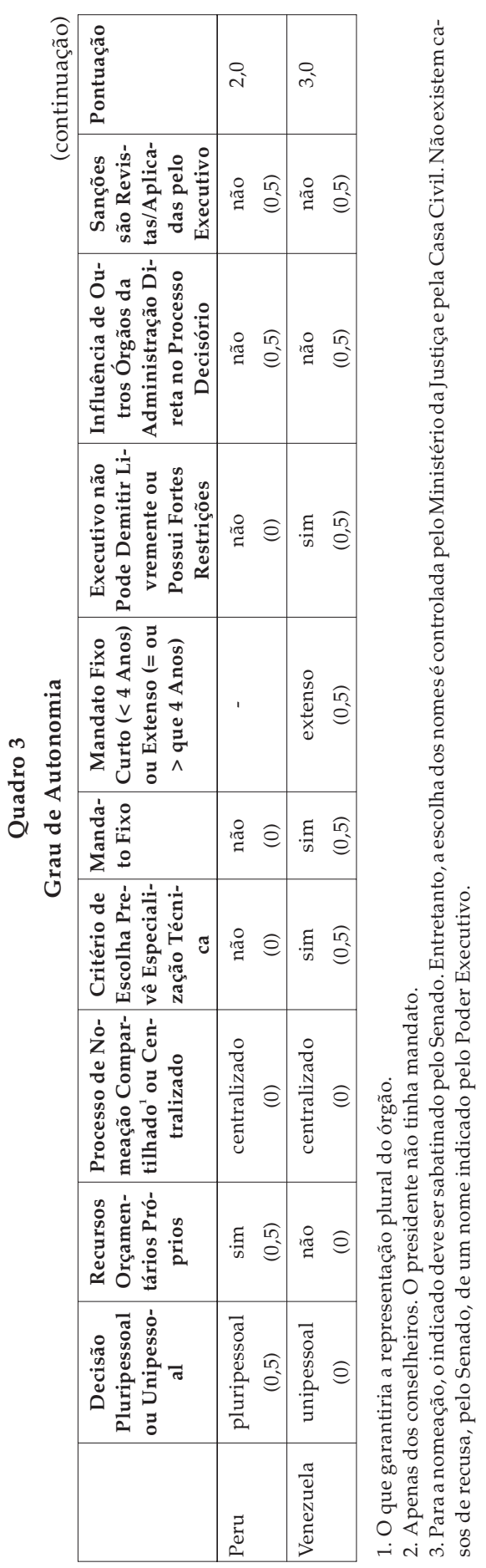


nais desde 1975, permite avaliar a hipótese no tempo e em cada país ${ }^{4}$. Nos países que possuem legislação antitruste, parece que a implementação da legislação, em geral, foi acompanhada por um movimento prévio de liberalização econômica:

Tabela 2

Criação da Legislação Antitruste e Crescimento Prévio do Grau de Liberdade Econômica

\begin{tabular}{l|c|c|c|c}
\hline \multirow{2}{*}{ País } & \multicolumn{2}{|c|}{ Índice G\&L } & \multicolumn{2}{c}{ Ranking G\&L } \\
\cline { 2 - 5 } & ano (-5) & ano 0 & ano (-5) & ano 0 \\
\hline Argentina (1980) & $3,1(1975)$ & $4,2(1980)$ & $72(1975)$ & $85(1980)$ \\
Argentina (1999) & $6,4(1995)$ & $7,2(2000)$ & $43(1995)$ & $30(2000)$ \\
Brasil (1994) & $4,1(1990)$ & $4,5(1995)$ & $100(1990)$ & $108(1995)$ \\
Chile (1973) & - & - & - & - \\
Chile (1979) & $3,5(1975)$ & $5,1(1980)$ & $71(1975)$ & $61(1980)$ \\
Colômbia (1957) & - & - & - & - \\
Colômbia (1992) & $4,9(1990)$ & $5,3(1995)$ & $77(1990)$ & $86(1995)$ \\
Peru (1994 e 1996) & $3,8(1990)$ & $6,2(1995)$ & $104(1990)$ & $56(1995)$ \\
Peru (1991) & $2,7(1985)$ & $3,8(1990)$ & $110(1985)$ & $104(1990)$ \\
Venezuela (1991) & $6,1(1985)$ & $5,4(1990)$ & $27(1985)$ & $54(1990)$ \\
México (1992) & $5,9(1990)$ & $6,2(1995)$ & $41(1990)$ & $56(1995)$ \\
Costa Rica (1994) & $6,8(1990)$ & $6,6(1995)$ & $17(1990)$ & $39(1995)$ \\
Panamá (1996) & $6,6(1990)$ & $7,6(1995)$ & $23(1990)$ & $11(1995)$ \\
Jamaica (1993) & $5,6(1990)$ & $6,5(1995)$ & $52(1990)$ & $41(1995)$ \\
\hline
\end{tabular}

Fonte dos Índices G\&L: Gwartney e Lawson $(1997 ; 2002)$.

Obs.: Tabela elaborada pelo autor.

Ano 0 é o índice mais próximo do ano de implementação da legislação. Por exemplo, o índice qüinqüenal mais imediato de implementação da legislação antitruste na Argentina, em 1999, é o de $2000(7,2)$. Ano (-5) significa o valor do índice qüinqüenal anterior, que, no caso argentino, seria o índice de $1995(6,4)$; desse modo, foi testada a correlação entre o grau de autonomia e o índice tido como mais próximo ao ano da implementação e o anterior (cinco anos antes). Possivelmente, o grau anterior de liberalização econômica tem influência mais forte do que o do ano da promulgação da lei, uma vez que as instituições serão desenhadas de acordo com as discussões legislativas anteriores, desde a introdução do projeto de lei, e durante a tramitação nas comissões específicas. 
De fato, a hipótese da relação entre o grau de autonomia do órgão antitruste e o de liberalização econômica no momento anterior ao da implementação da legislação apresenta resultados mais significativos:

Tabela 3

Relação entre Reformas Pró-mercado e Autonomia da Agência Antitruste

\begin{tabular}{l|c|c|c}
\hline País & Autonomia & Índice G\&L (0) & Índice G\&L (-5) \\
\hline Argentina - 1980 & 2,5 & 4,2 & 3,1 \\
Argentina - 1999 & 4,0 & 7,2 & 6,4 \\
Brasil & 3,0 & 4,5 & 4,1 \\
Chile & 3,0 & 5,1 & 3,5 \\
Colômbia & 1,5 & 5,3 & 4,9 \\
Costa Rica & 3,5 & 6,6 & 6,8 \\
Jamaica & 2,5 & 6,5 & 5,6 \\
México & 3,5 & 6,2 & 5,9 \\
Panamá & 3,5 & 7,6 & 6,6 \\
Peru & 2,0 & 6,2 & 2,7 \\
Venezuela & 3 & 5,4 & 6,1 \\
\hline correlação & & 0,476343 & 0,614525 \\
R2 & & 0,226903 & 0,37764 \\
\hline
\end{tabular}

Fonte dos Índices G\&L: Gwartney e Lawson (1997; 2002).

Obs.: Tabela elaborada pelo autor.

A Tabela 3 pode ser visualizada nos Gráficos 3 e 4 e nas suas respectivas linhas de tendência.

\section{Gráfico 3}

Relação entre o Índice Gwartney e Lawson Ano 0 (referente ao período da promulgação da lei) e a Autonomia das Agências Latino-Americanas

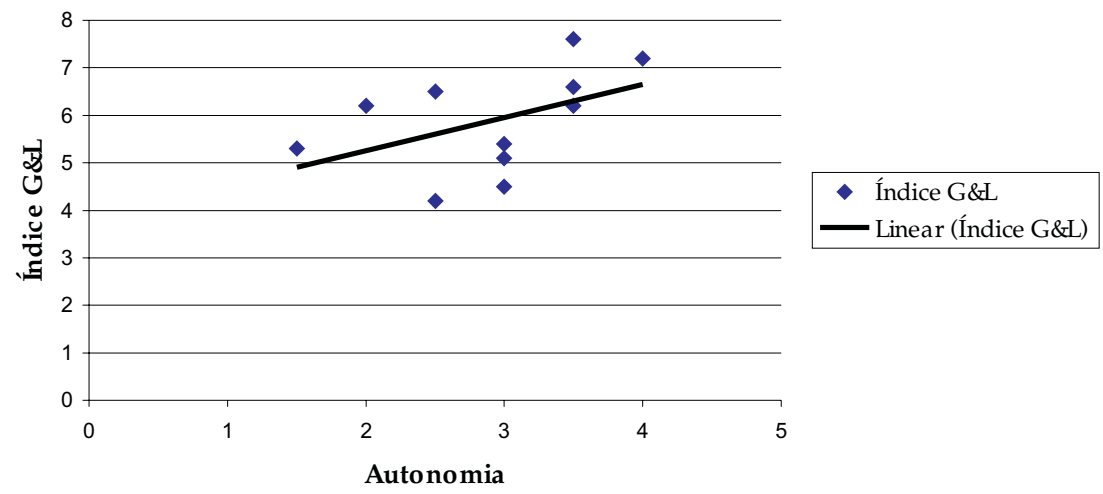

Correlação $=0,476343 ; \mathrm{R} 2=0,226903$ 


\section{Gráfico 4}

Relação entre o Índice Gwartney e Lawson Ano (-5) (referente ao período anterior ao da promulgação da lei) e a Autonomia das Agências Latino-Americanas

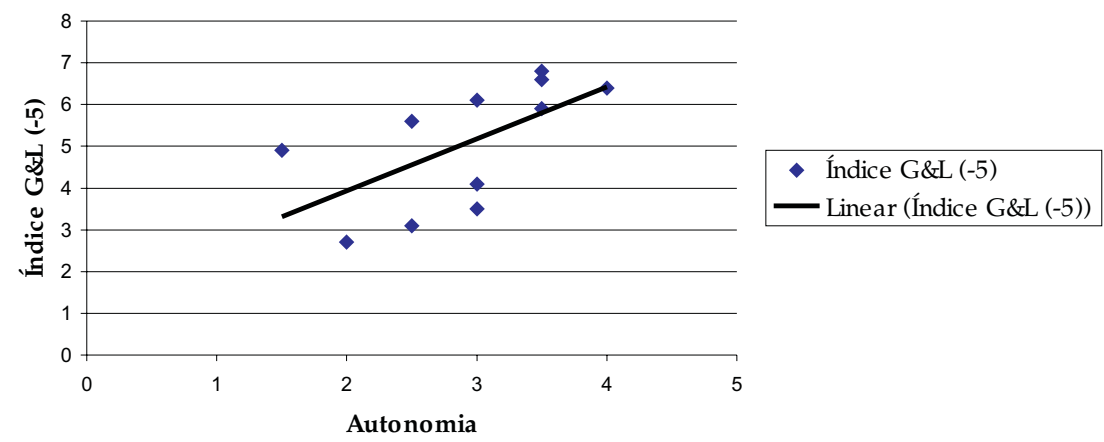

Correlação $=0,614525 ; \mathrm{R} 2=0,37764$

Os dados acima permitem concluir que há razoável tendência de se fornecer maior autonomia aos responsáveis pela política antitruste na medida em que a liberalização econômica é mais profunda. A resposta de cada país à pressão sistêmica gerada pelo processo de globalização é diversa. Não é observada nenhuma convergência institucional em favor da liberalização econômica, ou, pelo menos, a velocidade em sua direção é bastante distinta; conseqüentemente, é esperada a dispersão do grau de autonomia. Em países com menor grau de liberalização econômica, o ato de fornecer credibilidade regulatória gera menos benefícios para o Executivo, o que torna menos relevante a delegação de autonomia para as agências.

O conceito de liberdade econômica é baseado na idéia de que, em sociedades economicamente livres, a função principal do governo é proteger o direito de propriedade e a provisão de bens públicos. $\mathrm{O}$ uso do poder estatal, para decidir o que produzir e o que consumir, logicamente, viola a liberdade econômica. Uma maior eficácia da política corresponde não apenas ao controle mais efetivo do poder privado, mas também das pressões advindas do interior de segmentos do próprio Estado, que tendem a ameaçar a liberdade de produzir de outros participantes do mercado e restringem a escolha dos consumidores. Autonomia significa isolar o órgão antitruste dessas pressões ex- 
ternas sobre o processo decisório, o que eleva a probabilidade de decisões mais eficazes.

Não se quer aqui dizer que o processo de liberalização econômica seja o único fator relevante na determinação do grau de autonomia da agência antitruste; se assim o fosse, a correlação entre essas variáveis seria bem mais significativa. Em primeiro lugar, existe certa tendência de os países copiarem instituições que foram bem-sucedidas em outros países, razão pela qual, embora com variações, observa-se a tendência de se adotar o padrão regulatório norte-americano, baseado em agências independentes. Em segundo lugar, não só o peso da herança corporativa e o número de atores com poder de veto sobre a alteração dos rumos das políticas, como também as barreiras constitucionais e os fatores conjunturais afetam a autonomia da agência.

\section{CONCLUSÕES}

Na América Latina, a regulação antitruste oscila entre os objetivos de natureza conjuntural ou de política macroeconômica e os de formulação de compromissos críveis com o setor privado. Ocasionalmente, as autoridades governamentais utilizam a política antitruste como instrumento de ameaça de retaliação do Executivo contra setores da economia com forte impacto social (Forgioni, 1998:133) - como, por exemplo, o setor de combustíveis e de medicamentos, muitas vezes acusados de "aumentos abusivos de preços" -, o que inibe a geração de credibilidade regulatória.

Os dados apresentados no presente artigo permitem concluir que as escolhas do regime regulatório e das estruturas de incentivos levam em consideração o ambiente institucional mais amplo; em particular, o grau de autonomia é um possível resultado do equilíbrio entre duas forças antagônicas: a necessidade de realizar compromissos críveis em torno de regras entre o setor público e o privado - condição necessária para estimular investimentos privados - e o interesse governamental de manipular as decisões para fins políticos. A maior intensidade de reformas pró-mercado aumenta os custos econômicos e políticos resultantes da falta de autonomia da agência.

A correlação entre a autonomia da agência e a liberalização econômica é compatível com a tese de que o desenho institucional está associado à competição entre grupos de pressão. A reconfiguração do am- 
biente institucional em direção a um novo espaço público, no qual a intervenção direta é substituída por outra modalidade de intervenção - de natureza regulatória -, é resultado da pressão do setor privado para a proteção dos investimentos. O modelo desenvolvimentista, fundamentado na proteção da indústria doméstica, tende, no contexto da globalização, a gerar menos benefícios políticos. Como investimentos envolvem compromissos contratuais de longo prazo, a autonomia do órgão regulador sinaliza maior segurança quanto aos seus resultados futuros, isto é, o retorno do capital não estará vulnerável a eventuais intervenções do Executivo no segmento regulado.

A variável autonomia também depende do ambiente institucional prévio. O ranking dos órgãos de defesa da concorrência, formulado pela Global Competition Review (Quadro 2), é constituído, majoritariamente, por países-membros da Organização para a Cooperação e Desenvolvimento Econômico - OCDE. A resposta institucional desses países ao processo de globalização, com algumas exceções, não tem sido em direção a um modelo regulatório de agências independentes, como demonstra a fraca correlação entre os índices de liberdade econômica e o grau de autonomia das agências desses países (Gráficos 1 e 2). Por sua vez, na América Latina, a correspondência entre intensidade do processo de liberalização econômica e grau de autonomia das agências é bem mais significativa.

A obtenção de credibilidade regulatória, por meio de agências autônomas, foi a fórmula institucional adotada na América Latina. Outras condições - respeito às regras legais, accountability, bem como a transparência das instituições, estabilidade e consistência do sistema político, além de Judiciário neutro e independente, dentre outras -, algumas vezes frágeis na região, também facilitariam a formulação de compromissos críveis, independentemente do grau de autonomia das agências regulatórias. A tradição de intervenção e de corporativismo também age negativamente sobre as expectativas futuras dos investidores, o que obriga o Executivo a criar instituições que reduzam sua capacidade de intervir na política regulatória.

Portanto, na América Latina, a autonomia torna-se a variável mais relevante para o provimento de credibilidade aos agentes econômicos privados sobre os resultados da política regulatória. Estados latino-americanos são vistos como organizações fracas, incapazes de resistir a pressões por subsídios e proteção, além de pouco rígidos no 
cumprimento das leis. Como o Estado é particularmente vulnerável a pressões políticas, tanto na formulação quanto na implementação de políticas públicas, os resultados tendem também a ser muito incertos. A incerteza, em qualquer lugar do mundo, sempre existe; porém, uma coisa é lidar com a incerteza dado um conjunto de regras - neste caso, ao levar em consideração o espaço de atuação dos atores, é possível distribuir os resultados de forma probabilística. Outra situação ocorre em contextos em que as regras tendem a ser alteradas ou desrespeitadas - neste caso, os resultados possíveis não podem ser deduzidos das regras. A autonomia, nesse particular, fornece certo grau de segurança contra formas de expropriação e arbitrariedade administrativa.

(Recebido para publicação em novembro de 2003)

(Versão definitiva em abril de 2004)

\section{NOTAS}

1. Stigler considerava que a lei antitruste seria uma lei intrinsecamente de interesse público (ver Hazlett, 1984). Outros como Eckbo e Wier (1985) e Baumol e Ordover (1985) concluíram que a legislação antitruste tende a atender a interesses especiais.

2. Não é possível apreender as diversas fases da política antitruste americana sem se compreender o papel dos grupos de interesses e dos lobbies no Congresso americano e da inserção destes nos partidos Democrata e Republicano.

3. A atuação mais ou menos autônoma da agência também depende, por exemplo, da ideologia dos atores políticos.

4. O índice de Johnson e Sheehy apresenta séries somente a partir de 1995. 


\section{Alexandre Gheventer}

\section{REFERÊNCIAS BIBLIOGRÁFICAS}

AMATO, Giuliano. (1997), Antitrust and the Bounds of Power - The Dilemma of Liberal Democracy in the History of the Market. Oxford, Hart Publishing.

BAUMOL, William J. e ORDOVER, Janusz A. (1985), “Use of Antitrust to Subvert Competition". The Journal of Law and Economics, vol. 28, n- 2, pp. 247-265.

DAVIES, S.W. e LYONS, B. (1996), Industrial Organization in the Europe Union: Structure, Strategy and the Competitive Mechanism. Oxford, Oxford University Press.

ECKBO, B. Espen e WIER, Peggy. (1985), “Antimerger Policy under the Hart-Scott-Rodino Act: A Reexamination of the Market Power Hypothesis". The Journal of Law and Economics, vol. 28, nํ1, pp. 119-149.

FORGIONI, Paula A. (1998), Os Fundamentos do Antitruste. São Paulo, Ed. Revista dos Tribunais.

GWARTNEY, James e LAWSON, Robert. (1997), Economic Freedom of the World 1997 Annual Report. Vancouver, Fraser Institute.

(2002), Economic Freedom of the World 2002 Annual Report. Vancouver, Fraser Institute.

HAZLETT, Thomas W. (1984), "Interview with George Stigler". Reason, janeiro, pp. 44-48.

JOHNSON, Bryan T. e SHEEHY, Thomas P. (2002), 2002 Index of Economic Freedom. Washington, DC, The Heritage Foundation.

LANDE, Robert H. (1996), “Ascensão e Queda (Próxima) da Eficiência como Reguladora do Antitruste". Revista de Direito Econômico, no 23, pp. 39-65.

MEIER, Kenneth J. (1985), Regulation - Politics, Bureaucracy, and Economics. New York, St. Martin's Press.

NUNES, Edson. (1996), Política e Insulamento Burocrático: A Economia Política do Desenvolvimento Brasileiro. Rio de Janeiro/Brasília, Zahar Editores/ENAP.

OEA. (1997), “Transnational Corporations, Market Structure and Competition Policy”. World Investment Report 1997. United Nations on Trade and Development.

PRZEWORSKI, A. (1995), Estado e Economia no Capitalismo. Rio de Janeiro, Relume Dumará.

WEINGAST, B. R. e MORAN, M. J. (1983), “Bureaucratic Discretion or Congressional Control? Regulatory Policymaking by the Federal Trade Commission". Journal of Political Economy, vol. 91, no - 5, pp. 765-800. 


\section{ABSTRACT}

\section{Antitrust Policy and Regulatory Credibility in Latin America}

This article aims to analyze the relations between the process of institution-building and the broader historical and social setting, and particularly the relationship between the intensity of pro-market reforms and greater autonomy for the antitrust body. Autonomy is crucial in a regulatory format aimed at generating credibility in the stability of rules and thus reducing the level of uncertainty to which economic agents are exposed. Correlations between the institutional formulas adopted in Latin America and the rates of economic freedom indicate that choices concerning the regulatory regimen and incentives framework take the broader institutional environment into account.

Key words: antitrust; autonomy; Latin America; regulatory credibility; institutions; economic liberalization

\section{RÉSUMÉ}

\section{Politique Anti-trust et Crédibilité Régulatrice en Amérique Latine}

Dans cet article, on examine les relations entre le processus de formation d'institutions et un milieu historique et social plus large; en particulier, le rapport entre l'intensité des réformes en faveur du marché et la plus grande autonomie de l'agence anti-trust. L'autonomie est considérée une variable fondamentale dans un cadre régulatoire cherchant à créer de la crédibilité en ce qui concerne la stabilité des règles et, par là, à réduire le niveau d'incertitude qui touche les agents économiques. Le résultat des corrélations entre les formules institutionnelles adoptées en Amérique latine et des indicateurs de liberté économique permet de conclure que les choix à propos du régime régulateur et les structures d'incitation prennent en compte un milieu institutionnel plus large.

Mots-clé: anti-trust; autonomie; Amérique Latine; crédibilité régulatrice; institutions; libéralisation économique 